\title{
SYLVIA OSTROWETSKY EM VISITA A BELÉM
}

\author{
Edna Castro*
}

Sylvia Ostrowetsky, em sua única viagem a Belém, em 1996, percorreu alguns pontos da cidade com essa inquietação do olhar que atravessa todo o seu trabalho intelectual. Embora sua viagem fosse para proferir uma conferência no Núcleo de Altos Estudos Amazônicos, da Universidade Federal do Pará, ${ }^{1}$ sua expectativa em relação à cidade era visível. Uma certa curiosidade sobre essa cidade presente no imaginário europeu, quem sabe pelas narrativas de viajantes em diferentes épocas ou, ainda, pela sua localização em meio à imensa floresta tropical. Ao mesmo tempo, cidade como tantas outras no mundo, às margens de rios e com uma história de conflitos e de dominação colonial, cujo espaço produzido assinalava processos internos e tensões sobre a representação da sociedade e de seu imaginário e, em especial, sobre a ação dessa representação pela via de processos de intervenção direcionados a esse mesmo espaço.

Na sua conferência, Sylvia assinalou a relevância dessa conexão entre a história reinventada pela memória social da cidade e a ação do urbanismo marcada pela racionalidade do planejamento e da gestão do espaço. E, daí, as referências que faz sobre as Cidades Novas, os conjuntos habitacionais da $\mathrm{COHAB}$ localizados na região Metropolitana de Belém e construídos no final dos anos 60. Esses conjuntos foram justificados em função do déficit urbano e da necessidade de incentivar os investimentos na área da construção civil e que, tal qual as villes nouvelles da França, constituem estruturas saídas de um modelo de planejamento urbanístico experimentado nas pranchetas de arquitetos e engenheiros. Para Sylvia, o termo planejamento acabou por caracterizar nossas

\footnotetext{
* Professora da Universidade Federal do Pará - Núcleo de Altos Estudos Amazônicos. Doutora em Sociologia pela EHESS, Paris.
}

Artigo recebido em 29 set. 2004; aprovado em 3 nov. 2004. 
sociedades, como nomeação que invade o quotidiano das pessoas, assim como os termos comunicação de massa, grandes conjuntos, redes de circulação e informatização. Eles representam outra concepção de espaço enquanto gestão e algo a ordenar, lugares pensados para serem funcionais, sistemáticos e padronizados, ordem que ela não somente constata, mas toma como objeto de análise e crítica à luz de uma releitura de conceitos das ciências sociais.

As minhas lembranças sobre sua passagem por Belém ficaram marcadas pela sua personalidade ímpar e pela perspicácia que caracteriza o olhar interrogativo. Mas são lembranças fragmentadas, misturadas a passagens lidas em sua obra ou a fatos ocorridos em outros encontros posteriores, em Paris. Algumas dessas imagens em retalhos sobre Belém me vêem à memória como as referências sobre seus traços coloniais impressos na arquitetura dos casarios do bairro da Cidade Velha, o enobrecimento do final do século XIX e início do $\mathrm{XX}$, as praças - como as da República e Batista Campos -, ou ainda os pontos enquadrados nos valores urbanísticos de mercado. Os sinais da colonização identificados no Forte do Castelo, esse passado recomposto de cidades que surgiram e se constituíram tendo as fortificações como epicentro de um mundo colonial demarcado pelos símbolos da conquista e das estratégias defensivas. Belém com seus bairros que margeiam o rio Guamá ou frente à baia do Guajará e suas ilhas.

A leitura de seus textos, densos pela mediação teórica que consegue formular, exigem do leitor o exercício constante de abstração e de concentração. Selecionamos alguns deles para leitura e guia nas reflexões que seguem. Alguns conceitos fazem parte e são constantes no seu pensamento. Mas irei me restringir a considerações sobre os conceitos de espaço, tempo, representações e imaginário, ligados pela autora na sua crítica à razão moderna. A relação fundamental entre espaço e tempo não lhe escapa, pois cada cidade comporta uma dinâmica particular em suas diferentes dimensões do tempo histórico e social - passado, presente e futuro. O olhar que se impunha era o do distanciamento, no exercício de interpretação sociológica que caracteriza sua obra. 
O legado que nos deixou Sylvia, como uma autora que refletiu na contramão dos modismos que influenciaram a escolha de temas e de interpretações nas ciências sociais, nos incita a ir mais além no entendimento dos fundamentos da racionalidade do ator, da construção de sentidos, de representações e do imaginário social que permeia a produção social em diferentes épocas. Ela nos incita a uma releitura constante de nossas certezas. Pergunta-nos como fazer da cidade, ou do espaço, um objeto de estudo? E demonstra, em L'imaginaire batisseur (1983), a dimensão espacial do social, concluindo sobre a dimensão social do espaço, revisitando conceitos e atores caros à tradição sociológica e contribuindo, assim, para a construção da crítica sobre a razão urbanista da sociedade contemporânea.

Esse trabalho científico de rever o conceito de espaço se impõe, portanto, a partir de uma reflexão teórico-prática. O que aparecia para os outros como banal, resolvido, pode ser, como bem lembra, uma questão à explicação sociológica. Em Notas de leitura à guisa de prefácio ao livro de Sylvia, Louis Marin enquadra sua inquietação teórica na formulação do conceito de espaço que é, para ela, "uma dimensão constitutiva da sociedade, o que significa que ele não é somente o suporte técnico de uma atividade ou o suporte simbólico de uma organização - mas é, também, psiqué e materialidade”. Em síntese, há uma dialética de interação e de conflito, "de produção e de operação, na relação entre o social e o espaço". Assim, o urbanismo não pode ser entendido no absoluto mas, necessariamente, na relação com o lugar, com o espaço, e de sua dinâmica com o que é social. Nessa perspectiva, o conceito de espaço ultrapassa o sentido que lhes deram as ciências sociais e, em particular, na aplicação aos estudos urbanos.

Sylvia procura entender não somente a produção do espaço urbanístico em dado contexto social, cultural e político, mas captar a dinâmica de sua gestação, no ato de sua produção (semio-génèse), de um novo campo de luta na ação da representação da sociedade sobre ela mesma. Assim, na sua reflexão, o conceito de espaço ultrapassa os significados da linguagem pois tem como questão central desvelar uma conexão fundamental entre os discursos produzidos 
pelos urbanistas sobre o planejamento, incluindo aí a ação sobre os espaços planejados, e a representação do mundo e da sociedade. E, por isso, o caso que toma como exemplo em sua tese de doutorado (doctorat d'état) é o planejamento e a produção do espaço planejado das cidades novas enquanto processos de intervenção direta de um pensar a cidade a partir de estruturas da racionalidade de mercado e não dos sujeitos reais que vivem e fazem a dinâmica do lugar. $\mathrm{O}$ conceito de espaço, nessa perspectiva, se amplia, como assinala, pela representação da ação do saber sobre o mundo e a sociedade... pelo efeito de sua representação recíproca e de sua reflexão teórica e prática, como se refere em Les passeur en ville. Sylvia entende ser o espaço "representante, significante do significado social e não a obra onde sentido e materialidade se mesclariam em uma relação significante mais complexa e mais rica”.

O espaço social, a cidade e o urbano constituem o objeto mais preciso, se podemos assim dizer, da autora. Mas o desafio estava em apreender o campo de produção de um outro sentido da vida na cidades - a essência da cidade enquanto sentimento de habitar um lugar - e de suas dimensões, pelo exame do corpus constituído pelo material coletado na longa pesquisa realizada sobre as ações do planejamento em Paris, nos anos 60. Para a autora, o objetivo do urbanismo contemporâneo é dar um novo sentido ao espaço, pensar na ocupação de um vazio, e, daí, a criação das cidades novas, como uma forma planejada de ressocialização do espaço contemporâneo, cidades que se tornaram imaginadas e marginais a um conjunto de relações sociais reais negadas. No seu entender, as cidades produzidas pela égide da razão tecnicista, trazem essa marca de uma tentativa de naturalização subjetivada de objeto, ao mesmo tempo que essa neutralização objetiva do ator sociopolítico e técnico (Marin, 1983) pois o urbanismo, o mais freqüentemente, se objetiva pela via da demanda social.

Entendemos nas formulações de Sylvia, em L' imaginaire batisseur (1983), a síntese de uma crítica à modernidade. Essa talvez seja sua maior contribuição, ao rever as categorias, ao inverter sua compreensão, tomando a dimensão real do que é o sociológico e, 
para isso, volta aos clássicos, mas no sentido do encontro com as ciências sociais, de seus fundamentos e da reinterpretação à luz de categorias de uma dialética do espaço e do tempo. Essa crítica à modernidade é apresentada na primeira parte do livro L'imaginaire batisseur (1983) quando se dedica a mostrar um "deslocamento do símbolo à imagem" entendida como "possibilidade multiplicativa do real, característica da nossa pós-modernidade ocidental e construindo a noção de um sentido espacial irredutivel tanto a uma forma da sensibilidade quanto a um conceito operacional, à atividade de um sujeito pensante que a uma organização e a uma retórica da linguagem". Sylvia considera que se deve entender a produção contemporânea como não mais gerada pelo imaginário, mas com vantagens sobre os determinantes individuais, os grupos com estratégias parciais pois marcado pela complexidade da intervenção de múltiplas imagens.

Sobre as suas pesquisas comenta que o trabalho de revisão sobre o simbólico e o imaginário foi uma necessidade incontornável. A sua releitura postula novas hipóteses, como comenta na passagem:

Nossa análise se inscreve, entretanto no seio de um projeto de análise bem definido. O imaginário quer descrever aqui um tipo de renovação da sociabilidade, o que não exclui, é verdade, outros lugares mais restritos de persistência socializante de tipo clássico. O imaginário não visa aqui um lugar de interrogação geral, mas a descrição de um tipo de resposta social, este que domina os fenômenos de massa e nos quais nos incluímos, o espaço contemporâneo de nossas sociedades ocidentais. Este imaginário encontra seu fundamento como experiência primeira, comum, na imagem mental. Este imaginário constitui, e pelo menos é essa a nossa hipótese, um modo novo de relação do sujeito social com o mundo exterior.

Belém experimenta contemporaneamente a modernização vista em seu porto e nas áreas adjacentes. Constitui um processo explicado pelos urbanistas como de revitalização de áreas degradadas, em busca de novas funcionalidades, e, também, como cidade inserida no processo mais geral de modernidade pela via da modernização de todo o seu sistema portuário e de adaptações da cidade que "deve" incorporar competências para ser mais competitiva, atendendo às 
demandas de serviços de forma mais eficiente. Cidades competentes e competitivas por representarem um modelo formal, frio, urbanístico e que as torna objetos estranhos, destinados a serem mudados, inventados por indivíduos e grupos como entende Sylvia, ou, ainda, mercadorias, encaixotadas para o mercado que subordina atores sociais e suas dinâmicas.

Um primeiro ponto a ressaltar nessas mudanças é a multiplicidade dos processos de produção e de trabalho, das formas de comunicação, com a adoção de novas tecnologias e a implantação dos sistemas de rede, das organizações políticas e das demandas de direitos. Buscamos entender esses processos nas relações com a cidade de Belém, tomando como referência as dinâmicas internas e as dinâmicas externas, estas relacionadas às redes que têm vinculado cada vez mais as questões locais às globais. Um segundo ponto, o desafio de entender mudanças que estivessem possivelmente se verificando na relação da sociedade com o território a partir das cidades. Incursão que permitiria avançar na compreensão das rupturas e continuidades dos processos de modernização e identificar atores e protagonistas de uma dinâmica que inclui novos segmentos, mas não altera ao mesmo tempo as antigas estruturas de exclusão e de poder, reproduzindo o paradoxo do desenvolvimento e da marginalidade.

Modelos de modernização, via planejamento público comprometido com a intervenção do planejamento no espaço, têm trazido como desdobramento processos de desterritorialização de interesse locais. Uma das mais importantes experiências da ação do planejamento de Belém foi com o avanço da economia da borracha, que conectou a cidade a portos importantes do comércio mundial, acarretando mudanças em seu porto que representaram inovação e adequação do espaço às novas funções da cidade. $\mathrm{Na}$ atualidade, novos processo de modernização redefinem o espaço e as funções em certos bairros, seguindo uma racionalidade instrumental nos processos de mudança verificados na sua orla e no seu porto.

Paradoxalmente, identificam-se, de um lado, os sinais da adesão ou adaptação aos novos momentos que conformam as áreas urbanas, 
rapidamente integradas a circuitos de alta tecnologia, e, de outro, a reafirmação dos processos identitários, de constituição de sujeitos e de resistência. Isso porque as cidades são lugares das festas, dos arraiais, do trabalho de muitos, do comércio e das manifestações políticas. E de um saber sobre sua dinâmica. São também lugares onde os movimentos sociais se afirmam e constroem seus discursos e suas práticas em dado campo de luta. Essa contradição é resultado da turbulência nos tempos e espaços, nas transformações e permanências, ou da nostalgia do passado enquanto traço de uma sociedade que permaneceu nessas estruturas. A sociedade refaz seus passos, adotando, de forma parcial ou ampliada, o projeto de modernização, que se confunde no imaginário social contemporâneo com a integração nacional e internacional.

É nas cidades que acontecem os fóruns, as negociações e os diálogos. E também muitos conflitos encontram espaço de manifestação e visibilidade. Nesse sentido, é dialógico porque envolve os sujeitos e tem um campo da cooperação e do financiamento. Fronteira enquanto uma unidade socioterritorial pensada em relação à política de patrimônio social, político e cultural. E, evidentemente por isso, os espaços das cidades não são neutros. São espaços de disputas, um campo de luta por identidades, sonhos e projetos, onde as dimensões do real e do imaginário não escapam à noção de espaço social.

Finalmente, Sylvia antecipava uma visão interdisciplinar, que se impõe a despeito das interdições e da luta do campo, diferentes dos encontros pluridisciplinares como o proposto em Sociologues en ville (2000), publicação que, para ela, representa, modestamente, um "pequeno acontecimento no universo das ciências sociais". O sonho, para além de gerar impactos sobre a Maison Savante, que não é propriamente alcançar uma reflexão nem pluri e nem inter, é bem mais que isso, diz, uma vez que o desafio teórico é "desenhar um outro território do saber". Isso porque, para Sylvia Ostrowestsky, o indivíduo conhece sua cumplicidade profunda com o mundo histórico e social que o envolve, comentando que entre o objeto e o sujeito, a relação é mais do que de produção, é de conhecimento. Como 
os territórios das ciências sociais são o que lhe interessa, na sua crítica à trajetória às ciências sociais, ela nos alerta, chama a atenção para o exercício de pensar para elas se imporem e desconfiarem para que não se tornem os novos instrumentos da prática urbanística, instrumentos freqüentemente decepcionantes, um meio para o planejamento urbano se aproximar do social, mas numa perspectiva transfigurada, distante da perspectiva que busca $o$ entendimento da essência do social.

\section{Notas}

1 E também discutir com professores e alunos, sob iniciativa de Rosa Acevedo e Christian Azais, um possível espaço de intercâmbio de pesquisa como desdobramento do Convênio Capes-Cofecub, por mim coordenado (UFPA-NAEA e Universidade de Picardie, Amiens).

\section{Referências bibliográficas}

MARIN, Louis. Notas de leitura à guisa de prefácio. In: OSTROWETSKY, S. L'imaginaire bâtisseur. Paris: Méridiens-Klincksieck, 1983.

OSTROWETSKY, S. L'imaginaire bâtisseur. Paris: Méridiens-Klincksieck, 1983.

. Les passeurs en ville: introduction. In: . Sociologues en ville. Paris: L'Harmattan, 2000.

PINÇON, M.; PINÇON-CHARLOT, M. L'espace urbain comme expression symbolique de l'espace social. In: OSTROWETSKY, S. Sociologues en ville. Paris: L'Harmattan, 2000. 